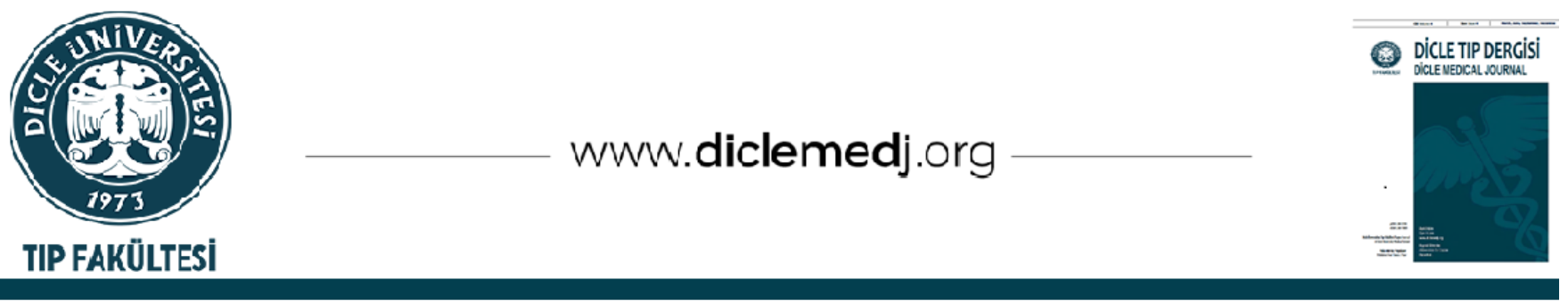

Original Article / Özgün Araştırma

\title{
Comparison of ventricular repolarization parameters including Tp-e, Tp-e/QTc, JTc and JTd during low-flow and high-flow desflurane anesthesia in gynecologic laparoscopic surgery
}

\author{
Berna Kaya Uğur ${ }^{D_{1}}$, Murat Sucu ${ }^{i}{ }_{2}$, Gülseren Karsli ${ }^{i}{ }_{3}$, Fatma Yilmaz Coşkun ${ }^{D_{2}}$, \\ Veysel İ. Düzen ${ }^{i}{ }_{2}$, Mete G. Uğur ${ }^{i D_{4}}$ \\ 1 Gaziantep University, Faculty of Medicine, Department of Anesthesiology and Reanimation, Gaziantep, Turkey \\ 2 Gaziantep University, Faculty of Medicine, Department of Cardiology, Gaziantep, Turkey \\ 3 Gaziantep Cengiz Gökçek Maternity and Children's Hospital, Department of Anesthesiology and Reanimation, Gaziantep, Turkey \\ 4 Gaziantep University, Faculty of Medicine, Department of Obstetrics and Gynecology, Gaziantep, Turkey
}

Received: 06.10.2020; Revised: 06.12.2020; Accepted: 07.12.2020

\begin{abstract}
Objectives: Low-flow anesthesia (LFA) gained reasonable popularity as it provides many advantages including physiological, ecological, economical issues. Desflurane is a preferable anesthetic in low-flow anesthesia practice however, the relation between QTc, QTd, and QTcd prolongation and management of anesthesia with desflurane has been previously demonstrated. We aimed to compare the effects of low-flow (LFA) and high-flow (HFA) desflurane anesthesia on hemodynamic changes and ventricular repolarization markers in gynecologic laparoscopy.

Methods: 58 patients were randomized into group L (LFA, $n=30)$ and group H (HFA, n=28). ECG was recorded before anesthesia and 60 th minute of anesthesia in both groups.

Results: JTc- 0 values were lower than JTc- 1 values within both group $\mathrm{L}$ and $\mathrm{H}$ ( $\mathrm{p}=0.001$ for both groups). JTcd- 0 and JTd- 1 values were lower than JTcd-1 within group H ( $\mathrm{p}=0.042$ and 0.002 , respectively). QTc-0 values were lower than QTc- 1 within both group L and group H ( $\mathrm{p}=0.001$ and 0.002 , respectively). QTcd-0 values were lower than QTcd- 1 within group H ( $\mathrm{p}=0.021)$. QTd-0 values were lower than QTd-1 within-group H ( $\mathrm{p}=0.026)$. Tpe- 0 and Tpe- 1 values were lower in group $\mathrm{L}(\mathrm{p}=0.001$ and 0.002 respectively). Also, JTc-0 values were lower than JTc- 1 values within both group $L$ and $H$ ( $p=0.021$ and 0.027 , respectively). Tpe/QTc- 1 ratio was significantly lower in group L ( $\mathrm{p}=0.010)$. The difference between Tpe/QTc-0 and Tpe/QTc-1 ratios within group H was significant ( $\mathrm{p}=0.028)$.

Conclusion: Our study showed that there was no significant difference between LFA and HFA in terms of ECG repolarization markers, which may predict the possibility of torsadogenity.
\end{abstract}

Keywords: Low-flow anesthesia; desflurane; ECG; arrhythmia; ventricular repolarization; QT; JT; Tpe

DOI: 10.5798/dicletip.850348

Correspondence / Yazışma Adresi: Berna Kaya Ugur, Gaziantep University, Faculty of Medicine, Department of Anesthesiology and Reanimation, Gaziantep, Turkey e-mail: bernakayaugur@hotmail.com 


\section{Jinekolojik Laparoskopik Cerrahide Düşük ve Yüksek Akımlı Desfluran Anestezisinin Tp- e,Tpe/QTc, JTc ve JTd gibi ventriküler repolarizasyon parametrelerine etkisinin karşılaștırılması}

\section{$\ddot{0} \mathbf{z}$}

Amaçlar: Düşük akımlı anestezi (DAA) fizyolojik, ekolojik, ekonomik konular dahil olmak üzere birçok avantajları nedeniyle son yıllarda popülerlik kazanmıştır. Desfluran, DAA uygulamasında tercih edilen bir anesteziktir, ancak desfluran ile anestezide QTc, QTd ve QTcd uzaması daha önceki çalışmalarda gösterilmiști. Çalışmamızda jinekolojik laparoskopide düşük akımlı ve yüksek akımlı (HFA) desfluran anestezisinin hemodinamik değișiklikler ve ventriküler repolarizasyon belirteçleri üzerindeki etkilerini karşılaştırmayı amaçladık.

Yöntemler: 58 hasta grup L (LFA, $n=30)$ ve grup H $(H F A, n=28)$ olarak randomize edildi. Her iki grupta da anestezi öncesi ve 60 . dakika anestezi EKG çekildi.

Bulgular: JTc-0 değerleri hem grup L hem de H içinde JTc-1 değerlerinden düşüktü (her iki grup için p = 0,001). Grup H içinde JTcd-0 ve JTd-1 değerleri JTcd-1'den düşüktü (sırasıyla p = 0.042 ve 0.002). QTc-0 değerleri hem grup L hem de grup H'de QTc-1'den düşüktü (sırasıyla $\mathrm{p}=0.001$ ve 0.002). Grup H içinde QTcd-0 değerleri QTcd-1'den daha düşüktü ( $\mathrm{p}=0.021)$. QTd-0 değerleri, grup H içinde QTd-1'den düşüktü ( $p=0.026)$. Grup L'de Tpe-0 ve Tpe-1 değerleri daha düşüktü (sırasıyla p = 0,001 ve 0,002). Ayrıca, hem L hem de H grubunda JTc-0 değerleri JTc-1 değerlerinden daha düşüktü (sırasıyla p = 0.021 ve 0.027). Grup L'de Tpe / QTc-1 oranı anlamlı olarak daha düşüktü ( $\mathrm{p}=$ 0,010). Grup H içinde Tpe / QTc-0 ve Tpe / QTc-1 oranları arasındaki fark anlamlıydı ( $\mathrm{p}=0,028)$.

Sonuç: Çalışmamızda, DAA ve YAA arasında EKG repolarizasyon belirteçleri ve torsadojenite riski arasında anlamlı bir fark olmadığı sonucuna varıldı.

Anahtar kelimeler: Düşük akım anestezi; desfluran; EKG; aritmi; ventriküler repolarizasyon; QT; JT; Tpe.

\section{INTRODUCTION}

In the era of minimally invasive medicine, combining a minimally invasive procedure with an ecological, physiological, and economical friendly anesthetic method makes more sense in modern anesthesia practice. However the chosen anesthetic method also must be also patient friendly and safe.

Low-flow anesthesia (LFA) gained a reasonable popularity as it provides many advantages including ecological issues, reduction of air pollution of operating room, decreased costs and prevention of airway desiccation.

Desflurane is relatively less soluble among the inhaled anesthetic agents and has advantageous pharmacologic characteristics and fast metabolism. These features make desflurane preferable in low-flow anesthesia practice ${ }^{1,2}$.

Ventricular repolarization (VR) is a complex electrical phenomenon and comprises an important step in cardiac electrical activity ${ }^{3-5}$. Markers of ventricular repolarization (VR) including QT interval (QT), corrected QT interval (QTc) intervals, QT dispersion (QTd), T peak to end (Tp-e), Tp-e/QTc, corrected JT interval (JTc) and JT dispersion (JTd) may help forecast arrhythmic events of ventricles and even sudden death. In previous studies, the relation between QTc6,7, QTd, and QTcd prolongation and management of anesthesia with desflurane has been demonstrated ${ }^{8}$.

The aim of this study is to compare the effects of LFA and HFA with desflurane on hemodynamic changes and ventricular repolarization parameters including QTc, QTd, QTcd, JTc, JTd, Tp-e, and Tp-e/QTc during gynecologic laparoscopic surgery.

\section{METHODS}

Sixty consecutive patients scheduled for diagnostic or operative laparoscopy combined with hysteroscopy for infertility with ASA I-II physical status were prospectively enrolled in the study between May 1st 2015 and January 1st 2016. Approval of the Faculty Ethical Committee and informed consents (verbal and written) were obtained (2015/189). We 
excluded patients less than 18 years of age or taking antiarrhythmic drugs or beta-blockers or patients with any cardiovascular disease or electrolyte imbalance from the content of the study. Echocardiography and electrocardiogram (ECG) were performed on all patients in order to rule out any cardiovascular disease before enrollment. Routine monitoring parameters, namely, ECG, heart rate (HR), non-invasive blood pressure (NIBP), oxygen saturation (SpO2), end-tidal $\mathrm{CO} 2$ (EtCO2) and gas monitoring were performed for all the patients. Demographic data of the participants' age, body mass index (BMI, $\mathrm{kg} / \mathrm{m} 2$ ), ASA physical status, operation and anesthesia time (minutes) were recorded. In order to avoid CO accumulation with desflurane, $\mathrm{CO} 2$ absorbent canisters (KNG SORB, KNG Medical, İzmir, Turkey) were refilled everyday. Randomization of the patients into two groups as group L (Lowflow desflurane anesthesia, $n=30$ ) and group $\mathrm{H}$ (High-flow desflurane anesthesia, $n=30$ ) was achieved with computer-generated random numbers. Pre-oxygenation was applied with $100 \%$ oxygen (02) at $6 \mathrm{~L} / \mathrm{min}$ for $3 \mathrm{~min}$ in all patients. ECG recordings (twelve leads) were performed before and 60 minutes after anesthetic induction in all patients. All patients were given intravenous (IV) fentanyl citrate (Talinat, Vem İlaç, İstanbul, Turkey), $2 \mu \mathrm{g} / \mathrm{kg}$ and propofol (Propofol, Fresenius Kabi, İstanbul, Turkey) $2-3 \mathrm{mg} / \mathrm{kg}$ followed by IV rocuronium bromide Rocuronium (Esmeron; MSD Pharma Hungary, Budapest, Hungary) 0.5 $\mathrm{mg} / \mathrm{kg}$ for endotracheal intubation. Anesthesia was maintained by administration of \%6-8 MAC desflurane (Suprane $\AA$, Baxter Healthcare, Deerfield, IL, USA). Intermittent positive pressure ventilation was initiated with a tidal volume of $7 \mathrm{ml} / \mathrm{kg}$, rate of $12 / \mathrm{min}$ with 02 and air in a ratio 40:60 with an FGF of $6 \mathrm{~L} / \mathrm{min}$ to maintain EtCO2 values between $35-45 \mathrm{mmHg}$ after endotracheal intubation.
The inspired and expired gas concentrations were measured each minute for the first 10 minutes to achieve steady state. Then total gas flow was reduced to $0.5 \mathrm{~L} / \mathrm{min}$ with $50 \%$ 02-air mixture in group $\mathrm{L}$.

The surgery was performed in routine gynecologic position (low lithotomy). We inserted a primary umbilical 12-mm trocar (for 10-mm 00 laparoscope) and ipsilateral two 5$\mathrm{mm}$ trocars for surgery. Surgeons decreased the pressure of pneumoperitoneum down to 12 mmHg after the insertion of all trocars. The degree of Trendelenburg position was less than 200 was used in both groups but 00 was preferred for hysteroscopy.

Conventional 12 lead ECG recordings at $25 \mathrm{~mm} / \mathrm{s}$ paper speed and $10 \mathrm{~mm} / \mathrm{mV}$ amplitude was used. Mean results were calculated from three consecutive cardiac cycles and parameters were determined in all 12 leads when possible. Any lead with a wave amplitude $<1.5 \mathrm{~mm}$ was excluded from analysis. A blinded cardiologist assessed ECG recordings manually. HR [baseline (HR-0), 60th minute (HR-1)], MAP (baseline and at the 60th minute), QTc [baseline (QTc-0), 60th minute (QTc-1)], QTd [baseline (QTd-0), 60th minute (QTd-1)], JTc [baseline (JTc-0), 60th minute (JTc-1)], JTd [baseline (JTd-0), 60th minute (JTd-1)], Tpe [baseline (Tpe-0), 60th minute (Tpe-1)] and Tpe/QTc [baseline (Tpe/QTc-0), 60th minute (Tpe/QTc1)] of patients in both groups were measured. The QT intervals were measured manually from the onset of QRS complex to the end of the T wave (defined as the intersection of isoelectric line and the tangent of the maximal downward limb of the $T$ wave). The QT interval was corrected for heart rate using the Bazett formula. QTd was defined as the difference between the maximum and minimum average of QT interval. The JTc interval was calculated by subtracting the QRS duration from the QTc interval. JTd was defined as the difference between the maximum and minimum average 
of JT interval. The Tpe interval was measured from the peak of the $\mathrm{T}$ wave to the end of the $\mathrm{T}$ wave. When $U$ waves were present, the end of the $\mathrm{T}$ wave was defined as the nadir of curve between the $\mathrm{T}$ and $\mathrm{U}$ waves. Tp-e/QTc interval ratios (Tp-e divided by a QTc) were also calculated as index of repolarization.

Then endotracheal intubation and mechanical ventilation with tidal volume of $8 \mathrm{ml} / \mathrm{kg}$, ventilation frequency of 12 breaths/min, inspiration-expiration ratio of 1:2, oxygen flow rate of $2 \mathrm{~L} / \mathrm{min}$ were performed, and the airway pressure, PETCO2, and SpO2 were maintained between 12-18 cmH20, 35-45 $\mathrm{mmHg}$, and 98$100 \%$ respectively. Any arrhythmic event of the patients was recorded through the study period.

The normality of distribution of continuous variables was analyzed by Shapiro-Wilk test. Student $\mathrm{t}$ test (for normal data) and MannWhitney U test (for non-normal data) were used for comparison of two independent groups and Wilcoxon tests were used to compare numerical variables measured at two different time points. This is a pilot study regarding the hypothesis, therefore we did not perform a power analysis. SPSS for Windows version 22.0 was utilized for statistical analysis and the difference was accepted as significant when the $\mathrm{p}$ value was below 0.05 .

\section{RESULTS}

Two patients in group $\mathrm{H}$ were excluded because of significant artifacts in the ECG recordings leading to unreliable readings and 58 patients were available for final analysis. No significant difference was revealed in terms of age, BMI, operation time, anesthesia time, laparoscopic surgery type, and ASA status between the groups (Table 1).

Hemodynamic parameters of patients during anesthesia were compared between the two groups. No significant difference was revealed in terms of MAP, SpO2 and HR values between the study groups at each observation period (Table 2).

Table I: Age, BMI, operation time, anesthesia time and ASA physical status of the patients.

\begin{tabular}{|l|l|l|c|}
\hline Variables & $\begin{array}{l}\text { Group } \\
(\mathrm{n}=30)\end{array}$ & Group H (n=28) & $\mathrm{p}^{*}$ \\
\hline Age & $38,93 \pm 11,42$ & $40,71 \pm 8,95$ & 0.513 \\
\hline BMI & $27,05 \pm 5$ & $28,86 \pm 5,65$ & 0.206 \\
\hline Operation time (min) & $92,17 \pm 18,08$ & $97,68 \pm 33,87$ & 0.814 \\
\hline Anesthesia time (min) & $105 \pm 18,89$ & $111,79 \pm 33,67$ & 0.963 \\
\hline Diagnostic & 11 & 10 & 0.940 \\
\hline Operative & 19 & 18 & \\
\hline ASA status & $10(33.3)$ & $10(35.7)$ & \\
\hline II & $30(66.7)$ & $28(64.3)$ & \\
\hline * Significant at $p<0.05$. & & & \\
\hline
\end{tabular}

Table II: Comparison of mean arterial pressure (MAP), Sp02 values between the groups.

\begin{tabular}{|l|l|l|l|}
\hline Variables & $\begin{array}{l}\text { Group L } \\
(\mathbf{n = 3 0})\end{array}$ & $\begin{array}{l}\text { Group } \\
\mathbf{( n = 2 8})\end{array}$ & $\mathbf{p}$ \\
\hline $\begin{array}{l}\text { Before induction } \\
\text { (\%) }\end{array}$ & $98,27 \pm 1,66$ & $98,14 \pm 1,56$ & 0,610 \\
\hline $60^{\text {th }}$ minute & $98,87 \pm 1,78$ & $98,68 \pm 2,31$ & 0,736 \\
\hline $\begin{array}{l}\text { Mean arterial } \\
\text { pressure }\end{array}$ & $98,37 \pm 18,17$ & $94,54 \pm 21,92$ & 0,862 \\
\hline Before induction & $87,07 \pm 12,88$ & $90,32 \pm 19,06$ & 0,895 \\
\hline $60^{\text {th }}$ minute & $85,07 \pm 15,33$ & $89,11 \pm 13,96$ & 0,338 \\
\hline Heart rate & $73,7 \pm 11,52$ & $78,04 \pm 14,83$ & 0,311 \\
\hline Before induction & & & \\
\hline $60^{\text {th }}$ minute \\
*Significant at $p<0.05$.
\end{tabular}

The heart rate, JTc, JTcd, JTd, QTc, QTcd, QTd, Tpe, and Tpe/QTc ratio values of groups depending on ECG readings are presented in table 3 and 4. 
Table III: Heart rate, JT, JTc, JTcd and JTd values of groups.

\begin{tabular}{|c|l|l|c|}
\hline Variables & Group L (n=30) & Group $\mathbf{H}(\mathbf{n = 2 8})$ & $\mathbf{p}$ \\
\hline HR-0 & $78.73 \pm 9.99$ & $77.5 \pm 17.13$ & 0.383 \\
\hline HR-1 & $74.77 \pm 10.95$ & $77.86 \pm 19.29$ & 0.864 \\
\hline & $\mathrm{p}=0.072$ & $\mathrm{p}=0.801$ & \\
\hline JTc-0 & $310.87 \pm 20.69$ & $317.50 \pm 34.08$ & 0.183 \\
\hline JTc-1 & $336.33 \pm 16.62$ & $341.18 \pm 29.18$ & 0.697 \\
\hline & $\mathrm{p}=0.001^{*}$ & $\mathrm{p}=0.001^{*}$ & \\
\hline JTcd-0 & $24.87 \pm 17.58$ & $19.96 \pm 8.54$ & 0.450 \\
\hline JTcd-1 & $24.2 \pm 13.31$ & $23.32 \pm 7.56$ & 0.932 \\
\hline & $\mathrm{p}=0.823$ & $\mathrm{p}=0.042^{*}$ & \\
\hline JTd-0 & $22.73 \pm 16.07$ & $16.43 \pm 6.47$ & 0.259 \\
\hline JTd-1 & $22 \pm 12.08$ & $21.14 \pm 6.85$ & 0.856 \\
\hline & $\mathrm{p}=0.818$ & $\mathrm{p}=0.002^{*}$ & \\
\hline
\end{tabular}

*Significant at 0.05 levels. HR: Heart rate

Table IV: QTc, QTcd, QTd, Tpe, and Tpe/QTc ratio values of groups.

\begin{tabular}{|c|l|l|c|}
\hline Variables & Group L (n=30 ) & Group H (n=28 ) & $\mathbf{p}$ \\
\hline QTc-0 & $400.43 \pm 23.77$ & $413.61 \pm 47.75$ & 0.088 \\
\hline QTc-1 & $432.43 \pm 25.78$ & $439.75 \pm 24.6$ & 0.331 \\
\hline & $\mathrm{p}=0.001^{*}$ & $\mathrm{p}=0.002^{*}$ & \\
\hline QTcd-0 & $23.23 \pm 15.17$ & $22 \pm 11$ & 0.646 \\
\hline QTcd-1 & $29.37 \pm 17.02$ & $27.39 \pm 10.28$ & 0.396 \\
\hline & $\mathrm{p}=0.143$ & $\mathrm{p}=0.021^{*}$ & \\
\hline QTd-0 & $20.33 \pm 13.51$ & $18.89 \pm 9.02$ & 0.740 \\
\hline QTd-1 & $26.33 \pm 15.81$ & $24.21 \pm 10.12$ & 0.405 \\
\hline & $\mathrm{p}=0.097$ & $\mathrm{p}=0.026^{*}$ & \\
\hline Tpe-0 & $77.7 \pm 15.79$ & $84.14 \pm 9.02$ & 0.07 \\
\hline Tpe-1 & $88.67 \pm 20.84$ & $101.07 \pm 11.73$ & $0.002^{*}$ \\
\hline & $\mathrm{p}=0.021^{*}$ & $\mathrm{p}=0.001^{*}$ & \\
\hline Tpe/QTc-0 & $0.19 \pm 0.04$ & $0.21 \pm 0.03$ & 0.109 \\
\hline Tpe/QTc-1 & $0.21 \pm 0.05$ & $0.23 \pm 0.03$ & $0.010^{*}$ \\
\hline & $\mathrm{p}=0.274$ & $\mathrm{p}=0.028$ & \\
\hline Significant at $0.05 l e v e l s$ & & \\
\hline & & & \\
\hline & & & \\
\hline & & & \\
\hline & & & \\
\hline & & & \\
\hline
\end{tabular}

${ }^{*}$ Significant at 0.05 levels.
No significant change both between and within the groups in terms of heart rate according to ECG was revealed.

The difference between the groups regarding JTc-0 and JTc-1 values was not significant ( $p=0.183$ and 0.697 , respectively). JTc-0 values were significantly lower than JTc-1 values within both group $\mathrm{L}$ and $\mathrm{H}(\mathrm{p}=0.001$ for both groups).

There was no significant difference between the groups and within group L in terms of JTcd-0 and JTcd-1 values. But JTcd-0 values were significantly lower than JTcd-1 within group $\mathrm{H}$ $(\mathrm{p}=0.042)$.

There was no significant difference between the groups and within group L in terms of JTd- 0 and JTd-1 values. But JTd-0 values were significantly lower than JTd-1 within group H $(\mathrm{p}=0.002)$.

There was no significant difference between the groups in terms of QTc- 0 and QTc- 1 values. QTc0 values were significantly lower than QTc-1 within both group L and group $\mathrm{H}(\mathrm{p}=0.001$ and 0.002 , respectively).

There was no significant difference between the groups and within group L in terms of QTcd-0 and QTcd-1 values. But QTcd-0 values were significantly lower than QTcd-1 within group H $(\mathrm{p}=0.021)$.

There was no significant difference between the groups and within group L in terms of QTd-0 and QTd-1 values. But QTd-0 values were significantly lower than QTd-1 within group $\mathrm{H}$ $(\mathrm{p}=0.026)$.

Tpe- 0 and Tpe- 1 values were significantly lower in group $\mathrm{L}(\mathrm{p}=0.001$ and 0.002 respectively). Also JTc- 0 values were significantly lower than JTc-1 values within both group $\mathrm{L}$ and $\mathrm{H}$ $(\mathrm{p}=0.021$ and 0.027 , respectively).

The difference between the groups regarding Tpe/QTc-0 ratio was not significant $(\mathrm{p}=0.109)$. Tpe/QTc-1 ratio was significantly lower in group L $(p=0.010)$. There was no significant 
difference between Tpe/QTc- 0 and Tpe/QTc-1 ratios within group $\mathrm{L}(\mathrm{p}=0.274)$, but there was a significant difference between these ratios within group $\mathrm{H}(\mathrm{p}=0.028)$.

\section{DISCUSSION}

Low-flow and minimal-flow anesthesia use in routine clinical anesthetic practice did not gain wide popularity, although studies concerning low-flow anesthesia are increasing. High-flow anesthesia is still preferred by many anesthesiologists depending on the long clinical experience, prevention of possible hazards including arrhythmias, hypoxia, CO accumulation, and awareness.

During general anesthesia and endotracheal intubation, the respiratory tract behaves as a large heat and moisture exchanger. Because of the by-pass effect of endotracheal intubation, the upper airway of the patient cannot heat and moisture the cold and dry gas that absorbs the heat and moisture of the patient. For maintaining the body temperature and decreasing the loss of humidity, warmed and moistened anesthetics gas has to be applied ${ }^{9}$.

In routine general anesthesia practice, an anesthetic circle breathing system preserves moisture and heat by rebreathing of exhaled gas that contains water and heat of expirium gas of the patient and releasing of water vapor and heat from $\mathrm{CO} 2$ absorbent, which creates an exothermic reaction ${ }^{10}$.

A viewpoint of advantages regarding LFA may be the positive physiological effects of LFA on the respiratory tract as we have previously suggested.

Special patient groups with a limited physiologic capacity of pulmonary and/or cardiac reserves are more prone to such airway temperature and humidity alterations ${ }^{11}$.

VR is one of the most important contributors of complex electrical occurrences that constitute a critical step in electrical activity of the heart. VR is defined as the time between the onset of the QRS wave complex and the end of the T wave in ECG. Any change in cardiac electrical activity may lay the groundwork to mortal arrhythmias by means of producing various alterations in repolarization ${ }^{12}$.

Anesthetics used in clinical practice may have various effects on the ECG parameters. Many volatile anesthetics such as sevoflurane, isoflurane, and desflurane are known to prolong QT interval ${ }^{13}$.

Sympathetic activation caused by desflurane, activates renin-angiotensin-aldosterone system and increases vasopressin and catecholamine concentration ${ }^{14}$.

In healthy volunteers, desflurane at 1.0-1,5 MAC has been shown to cause significant sympathetic excitation and results in hypertension and tachycardia 15 . These sympathetic activations exerted by desflurane causes hemodynamic changes that have effects on cardiac electrophysiology ${ }^{16}$.

There is a strong correlation with the prolongation of QTc and ventricular arrhythmia

17. In the present study, there was a prolongation of QTc in both groups between baseline and the 1st hour ECG recordings, which is more remarked in group $H$. These prolongations in QTc theoretically make the patients more prone to ventricular arrhythmias.

Another perspective is that our study population is homogenously composed of healthy women. This eliminates potential bias regarding gender, because QT prolongation after such medications, and TdP-type arrhythmias are observed more in women compared with men. Also, this constitutes the logic of our hypothesis to test the effect of two different desflurane anesthesia methods on ventricular repolarization parameters in such a population with relatively more risk of arrhythmia 18,19 . 
Fortunately, there was no occurrence of arrhythmia in both groups in our study. LFA has some potential physiological advantages and has less physiological burden on the patient as it protects the airway from the non-physiologic effect of HFA. Although mean QTc interval was longer in HFA group, the difference in QTc interval between the two groups at the 1st hour ECGs was not significant.

Transmural dispersion of repolarization can be measured by a relatively novel parameter $\mathrm{T}$ peak to T-end (Tpe) ${ }^{3}$.

The risk for life-threatening ventricular arrhythmias and sudden death in patients with a normal QTc can be calculated upon some parameters but Tpe interval has better predictive performance 4 . Any prolongation in Tpe interval effects the excitation and conduction, and induces TdP. In the study of Liu et al. the effect of desflurane on Tpe interval in three groups with different MAC values at the same FGF rates was investigated and no significantly different prolongation was reported 20 . The authors concluded that desflurane does not have an effect on ventricular transmural dispersion. But in our study, we found contradicting results. Tpe interval is prolonged in both groups between baseline and the 1st hour. According to the results of our study desflurane prolongs Tpe interval at the same MAC and at different FGF rates. The Tpe prolongation at the first hour is significantly longer in HFA compared with LFA. This finding also raises concerns regarding potential arrythmogenic effect with HFA.

The ratio of Tpe/QT is the ratio of relative to total ventricular refractory period. The higher the ratios the higher proportion of the relative refractory period, so the higher probability of cardiac electrical re-entry ${ }^{20}$. The ratio of Tpe/QT helps us to predict ventricular arrhythmia risk without the effect of HR20 and this why we preferred the Tpe/QTc ratio, as QTc is more reliable than QT. In our study Tpe/QTc ratio at the first hour is higher in Group $\mathrm{H}$ compared to group L. The reason for the higher Tpe/QTc ratio in HFA may be the physiological burden of the HFA. Also in the LFA group, one hour of low FGF rates may help protect the heat and moisture of the inspired air and makes the airway environment close to normal physiology as previously discussed.

JT interval, another repolarization parameter that involves both depolarization and repolarization periods, has better performance than QT intervals in representing specific repolarization time particularly in patients with prolonged QRS duration ${ }^{5}$. Desflurane has been shown to prolong ventricular repolarization parameters and the findings of our study are similar with the literature Jtc, Jtcd, and Jtd was prolonged in group $\mathrm{H}$, but only Jtc was prolonged in group $\mathrm{L}^{21}$.

These findings may support that HFA can have a disadvantage, however no patient in both study groups had clinically relevant arrhythmias. But also it should be considered that the patient population in this current study consisted of healthy and young patients. In order to evaluate the possible deleterious effects of HFA with desflurane in vulnerable and risky populations, further large-scaled studies in special patient groups are needed.

Our study may be criticized that there may be confounding effects of laryngoscopy and intubation through sympathetic stimulation on ECG parameters. In order to homogenize the interference of sympathetic stimulation and tracheal intubation, we included the ECG recordings at 1 st hour.

Also another confounding factor in our study was to choose propofol as the induction agent. We applied propofol for induction of anesthesia and to attenuate the sympathetic stimulation of laryngoscopy in both study groups. And besides, we applied $2 \mu \mathrm{g} / \mathrm{kg}$ of intravenous fentanyl to contribute to propofol. Fentanyl has no effect on 
the duration of repolarization at clinical doses in patients without cardiac pathology22,23.

However no significant effect of propofol on the duration of QTc in adults without cardiac pathology has been suggested in most of the studies ${ }^{19,24,25}$.

Experimental studies also concluded the clinical results suggesting that propofol has no effect on QTc interval26.

Furthermore some studies found that propofol may even shorten the QT and QTc intervals 25,27 and this effect may reverse the QTc prolongation originated by sevoflurane ${ }^{28}$.

According to these studies we may suggest that propofol may have no effect or attenuate the effect of sympathetic stimulation caused by laryngoscopy and concurrently sympathetic stimulation caused by desflurane. The significant prolongation of QTc in both groups even after propofol may depict the effect of desflurane.

Since the day John Snow noted that a significant amount of anesthetic gas was found in expired air from the patients unchanged in the early $1850 \mathrm{~s}$, it is one of the major problems of anesthesia providers to decrease the pollution of exhaled anesthetic gases. During routine anesthetic practice, an excessive amount of anesthetic gas emission to the atmosphere causes environmental pollution.

Most commonly used volatile anesthetics, namely, sevoflurane, desflurane, and isoflurane are very slightly metabolized in vivo ${ }^{29}$ and are scavenged to atmosphere as medical wastes with no or little degradation. They have the potential to behave like greenhouse gas as they have a long half-life in the atmosphere ranging between 1.4 and 21.4 years ${ }^{30}$. Thus, choosing lower FGFs as possible would help reduce the environmental impact of anesthetics because of minimal volatile agent consumption.
A possible cause of avoidance of LFA in clinical practice may be safety concerns. Our study showed that there was no significant difference between LFA and HFA regarding ECG repolarization markers, which may predict the possibility of torsadogenity. In light of our results, it is prudent not to hesitate for safety concerns of arrythmogenic potential of low flow desflurane anesthesia. As studies concerning the safety of LFA increase, the avoidance behavior of anesthesia providers on preferring LFA may decrease and may contribute to the preference of this rather environment-friendly anesthetic method. There is an evident need for larger scaled further studies with other patient groups.

Ethics Committee Approval: Approval of the Faculty Ethical Committee and informed consents (verbal and written) were obtained (2015/189).

Declaration of Conflicting Interests: The authors declare that they have no conflict of interest.

Financial Disclosure: No financial support was received.

\section{REFERENCES}

1. Johansson A, Lundberg D, Luttropp HH. Low-flow anaesthesia with desflurane: Kinetics during clinical procedures. Eur J Anaesthesiol. 2001; 18: 499-504.

2. Soyalp C, Dostbil A, Çelik M, et al. The effects of desflurane and remifentanyl anaesthesia compared to lumbar epidural analgesia combined with desflurane on recovery. Dicle Med J 2014; 41: 640-6.

3. Chugh SS, Reinier K, Singh T, et al. Determinants of prolonged QT interval and their contribution to sudden death risk in coronary artery disease. Circulation 2009; 119: 663-70.

4. Panikkath R, Reinier K, Uy-Evanado A, et al. Prolonged Tpeak to tend interval on the resting electrocardiogram is associated with increased risk of sudden cardiac death. Circ Arrhythm Electrophysiol 2011; 4: 441-7. 
5. Crow RS, Hannan PJ, Folsom AR. Prognostic significance of corrected QT and corrected JT interval for incident coronary heart disease in a general population sample stratified by presence or absence of wide QRS complex: the ARIC study with 13 years of follow-up. Circulation 2003; 108: 19859.

6. Yildirim H, Adanir T, Atay A, Katircioglu K, Savaci S. The effects of sevoflurane, isoflurane and desflurane on QT interval of the ECG. Eur J Anaesthesiol 2004; 21: 566-70.

7. Altunbas G, Sucu M, Zengin O. Ventricular repolarization disturbances after high dose intravenous methylprednisolone Theraphy. J Electrocardiol. 2018 Jan-Feb; 51: 140-4.

8. Silay E, Kati I, Tekin M, et al. Comparison of the effects of desflurane and sevoflurane on the QTc interval and QT dispersion. Acta Cardiol. 2005 Oct; 60: 459-64.

9. Pirbudak Cocelli L, Ugur MG, Karadasli H. Comparison of effects of low-flow sevoflurane and desflurane anesthesia on neutrophil and T-cell populations. Curr Ther Res Clin Exp. 2012; 73: 4151. doi:10.1016/j.curtheres.2012.02.005

10. Foregger $R$. The regeneration of soda lime following absorption of carbondioxide. Anesthesiology 1948; 9: 15-20.

11. Branson RD, Campbell RS, Davis K, Porembka DT. Anaesthesia circuits, humidity output, and mucociliary structure and function. Anaesth Intensive Care.

12. Yilmaz Coşkun F, Elboğa G, Altunbaş G, et al. Evaluation of ventricular repolarization features with Tp-e, Tp-e/QTc, JTc and JTd during electroconvulsive therapy. J Electrocardiol. 2018; 51: 440-2.

13. Staikou C, Stamelos M, Stavroulakis E. Impact of anaesthetic drugs and adjuvants on ECG markers of torsadogenicity. Br J Anaesth. 2014; 112: 217-30.

14. Weiskopf RB, Moore MA, Eger EI 2nd, et al. Rapid increase in desflurane concentration is associated with greater transient cardiovascular stimulation than with rapid increase in isoflurane concentration in humans. Anesthesiology. 1994 May; 80: 1035-45.
15. Ebert TJ., Muzi M. Sympathetic hyperactivity during desflurane anesthesia in healthy volunteers. A comparison with isoflurane. Anesthesiology. 1993; 79: 444-53.

16. Stewart GM, Kavanagh JJ, Koerbin G, Simmonds MJ, Sabapathy S. Cardiac electrical conduction, autonomic activity and biomarker release during recovery from prolonged strenuous exercise in trained male cyclists. Eur J Appl Physiol. 2014; 114: 1-10.

17. Paksoy F, Ulaş T, Bes C, Dal MS, Borlu F. Corrected Qt interval in patients with metabolic syndrome. Dicle Med J 2011; 38: 274-7.

18. Tadros R, Ton AT, Fiset C, Nattel S. Sex differences in cardiac electrophysiology and clinical arrhythmias: epidemiology, therapeutics, and mechanisms. Can J Cardiol. 2014; 30: 783-92.

19. Kuenszberg E, Loeckinger A, Kleinsasser A, et al. Sevoflurane, but not propofol, significantly prolongs the Q-T interval. Anesth Analg. 2000 Jan; 90: 25-7.

20. Liu Y, Fu X, Gao H, et al. Effects of different concentrations of desflurane on the index of cardiac electrophysiological balance in gynecologic surgery patients. Can J Physiol Pharmacol. 2020 May; 98: 332-335.

21. Aypar E, Karagoz AH, Ozer S, Celiker A, Ocal T. The effects of sevoflurane and desflurane anesthesia on QTc interval and cardiac rhythm in children. PaediatrAnaesth 2007; 17: 563-7.

22. Cafiero T, Di Minno RM, Di Iorio C. QT interval and QT dispersion during the induction of anesthesia and tracheal intubation: a comparison of remifentanil and fentanyl. Minerva Anestesiol 2011; 77: $160-5$.

23. Chang DJ, Kweon TD, Nam SB, et al. Effects of fentanyl pretreatment on the QTc interval during propofol induction. Anaesthesia. 2008 Oct; 63: 1056-60.

24. Michaloudis DG, Kanakoudis FS, Petrou AM, Konstantinidou AS, Pollard BJ. The effects of midazolam or propofol followed by suxamethonium on the QT interval in humans. Eur J Anaesthesiol 1996; 13: 364-8.

25. Kleinsasser A, Lindner $\mathrm{KH}$, Puehringer $\mathrm{F}$, Hoermann C. Sevoflurane progressively prolongs 
the QT interval in unpremedicated female adults. Eur J Anaesthesiol 2000; 17: 662-4.

26. Han DW, Park K, Jang SB, Kern SE. Modeling the effect of sevoflurane on corrected QT prolongation: a pharmacodynamic analysis. Anesthesiology 2010; 113: 806-11.

27. Higashijima U, Terao Y, Ichinomiya T, et al. A comparison of the effect on QT interval between thiamylal and propofol during anaesthetic induction. Anaesthesia 2010; 65: 679-83.

28. Kleinsasser A, Loeckinger A, Lindner $\mathrm{KH}$, et al. Reversing sevoflurane-associated QTc prolongation by changing to propofol. Anaesthesia 2001; 56: 24850.

29. Kazanci D, Unver S, Karadeniz U, et al. A comparison of the effects of desflurane, sevoflurane and propofol on QT, QTc, and P dispersion on ECG. Ann Card Anaesth. 2009 Jul-Dec; 12: 107-12.

30. Langbein T, Sonntag H, Trapp D, et al. Volatile anaesthetics and the atmosphere: atmospheric lifetimes and atmospheric effects of halothane, enflurane, isoflurane, desflurane and sevoflurane. $\mathrm{Br}$ J Anaesth. 1999 Jan; 82: 66-73. 